\title{
La asesoría jurídica y sus potenciales contribuciones a la educación, capacitación e información cooperativas en Cuba
}

\author{
(Legal counseling and its potential contributions to \\ cooperative education, training and information in Cuba)
}

Orestes Rodríguez Musa ${ }^{1}$

Orisel Hernández Aguilar²

Universidad de Pinar del Río (Cuba)

Sumario: I. Introducción II. La dimensión educativa dentro del Modelo del Profesional del Derecho en Cuba: particularidades para la asesoría jurídica. III. Marco legal de la labor educativa e informativa del asesor jurídico en las cooperativas cubanas. IV. Algunas propuestas para potenciar la educación, capacitación e información cooperativas en Cuba desde la asesoría jurídica V. Conclusiones.

Summary: I. Introduction II. The educational dimension within the Model of the Law Professional in Cuba: particularities for legal advice. III. Legal framework of the educational and informative work of the legal adviser in Cuban cooperatives. IV. Some proposals to promote cooperative education, training and information in Cuba from legal advice V. Conclusions.

Resumen: El modelo socioeconómico cubano de las últimas seis décadas se ha caracterizado por un Estado fuerte, que en sus relaciones con las cooperativas ha sido absorbente. Esta dinámica también ha llegado a la educación, capacitación e información de estas formas asociativas, así como a su asesoría jurídica. El presente trabajo tiene como objetivo fundamentar algunas ideas sobre la incidencia de la asesoría jurídica en la educación, capacitación e información en las cooperativas cubanas. Con este propósito, se analiza el lugar que ocupa la dimensión educativa en el Modelo del Profesional del Derecho en Cuba. A continuación, se explica el marco legal en el que se desarrolla la labor educativa e informativa del asesor jurídico en las cooperativas. Sobre esta base, se argumentan un grupo de recomendaciones para perfeccionar esta actividad.

1 E-mail: musa@upr.edu.cu

2 E-mail: oriselha@upr.edu.cu 
Palabras claves: asesoría jurídica; educación, capacitación e información cooperativas.

Abstract: The Cuban socioeconomic model of the last six decades has been characterized by a strong state, which has been absorbing in its relations with cooperatives. This dynamic has also reached the education, training and information of these associative forms, as well as their legal advice. The present work aims to base some ideas on the incidence of legal advice in education, training and information in Cuban cooperatives. With this purpose, the place of the educational dimension in the Model of the Professional of Law in Cuba is analyzed. Next, the legal framework in which the educational and informative work of the legal adviser in cooperatives is carried out is explained. On this basis, a group of recommendations are made to improve this activity.

Keywords: legal advice; cooperative education, training and information. 


\section{Introducción}

Como señalan Arnáez Arce y Atxabal Rada «Desde sus orígenes, el movimiento cooperativo ha tenido un compromiso claro y firme con la educación. No debemos olvidar que el desarrollo del modelo de cooperación de Rochdale y su funcionamiento fueron el resultado directo de un proceso de Educación-Aprendizaje ${ }^{3} \gg(2015,79)$. Por ello es perfectamente comprensible que el quinto principio de la Declaración sobre la Identidad Cooperativa, aprobada en el Congreso de Manchester en 1995, fuera el de «Educación, capacitación e información», definido en los términos que siguen: "Las cooperativas brindan educación y capacitación a sus asociados, representantes elegidos, funcionarios y empleados, de manera que puedan contribuir efectivamente al desarrollo de ellas. Informan al público en general, particularmente a los jóvenes y a los líderes de opinión, acerca de la naturaleza y los beneficios de la cooperación» (Alianza Cooperativa Internacional, 1995).

Las solas acciones que dan nombre al principio evidencian la amplitud del mismo. La educación puede ser entendida como un proceso constante en la vida a través del cual, se adquieren conocimientos, habilidades, creencias, valores o hábitos, por distintos métodos y en grados diversos de profundidad. La capacitación, sería entonces, una modalidad educativa encaminada particularmente a crear conocimientos técnicos, teóricos y prácticos en los individuos para el desempeño de una determinada actividad. Por último, la información supone el acceso a un grupo organizado de datos, relativos a un ente o fenómeno, que integran un mensaje y permiten que se adquiera el nivel de conocimiento necesario para la toma de decisiones.

Si se examina con detenimiento se hace notorio, además, que este principio entraña una doble perspectiva: una interna, que consiste en la educación y las actividades formativas dirigidas a los socios, a los directivos, representantes y empleados de las cooperativas y otra externa, que se concreta en las actividades informativas, de difusión y divulgación de los principios y valores cooperativos a la sociedad en general, a los líderes de opinión y a las administraciones públicas (Arnáez Arce, 2015, 190).

En Cuba, el modelo socioeconómico socialista asumido durante las últimas seis décadas, se ha caracterizado por un Estado fuerte, que en sus relaciones con las cooperativas ha sido - como regla - absorbente. Esta dinámica también ha llegado a la educación, capacitación e infor-

3 Traducción de los autores. 
mación de las cooperativas, así como a la asesoría jurídica de estas formas asociativas. Al respecto, téngase en cuenta que la educación y la capacitación de los socios ha llegado, generalmente, motivada por un interés público a través de acciones oficiales direccionadas, más que del acompañamiento que considere sus intereses y necesidades. Por su parte, los asesores jurídicos de las cooperativas cubanas, no sostienen con ellas vínculos laborales y mucho menos societarios, sino que estos desempeñan su labor en representación de otras entidades encargadas de esta función.

Teniendo en cuenta este contexto, el presente trabajo tiene como objetivo fundamentar algunas ideas que ilustren sobre la posible incidencia de la asesoría jurídica en la educación, capacitación e información en las cooperativas cubanas. Con este propósito, inicialmente se analiza el lugar que ocupa la dimensión educativa en el Modelo del Profesional del Derecho en Cuba. A continuación, se explica el marco legal en el que se desarrolla la labor educativa e informativa del asesor jurídico en las cooperativas cubanas. Sobre esta base, se argumentan un conjunto de recomendaciones que pueden contribuir a perfeccionar la aludida actividad.

\section{La dimensión educativa dentro del Modelo del Profesional del Derecho en Cuba: particularidades para la asesoría jurídica}

El modo de actuación, según Addine Fernández, es una generalización de los métodos profesionales que hace posible el actuar sobre los diferentes objetos inherentes a la ocupación. Este es el resultado de la asimilación por el egresado de los contenidos esenciales de la ciencia durante el proceso de formación, el cual debe haber estado en interacción con la lógica esencial de la profesión (Addine Fernández 2006, 1).

Siguiendo esta línea de pensamiento, Alfonso Caveda apunta que «el modo de actuación profesional, al ser generalización de los métodos de trabajo del profesional, se configura a partir de potenciar el máximo nivel de integración de núcleos de conocimientos, invariantes de habilidades y valores de las áreas disciplinares, en la solución de los problemas presentes en los objetos de trabajo, a través de lo cual se va construyendo el objeto de la profesión, en el tránsito del estudiante por cada uno de los años de su proceso de formación, expresando la lógica con que actúa y su identidad profesional» (Alfonso Caveda 2014,6 ).

Como consecuencia de esta concepción, en este término de la pedagogía se comprenden otras categorías del macrodiseño curricular 
(González Jiménez 2005). Así pues en los planes de estudios, al referirse al Modelo del Profesional, se parte de una caracterización de la carrera y de la profesión, dando paso a la determinación de su objeto, los principales problemas que esta debe resolver, sus modos de actuación, campos de acción, esferas de actuación y las funciones principales del profesional, todo lo cual, como es lógico debe guardar una estrecha relación.

En el Plan de Estudios D de la Licenciatura en Derecho se consideró que una generalización de las multifacéticas actividades del jurista conducía a "distinguir con claridad cuatro grandes modos de actuación del egresado: la asesoría, la representación, el control y preservación de la legalidad y la impartición de justicia» (Comisión Nacional de Carrera 2008, 9). Si bien entonces la Comisión Nacional de Carrera no contempló un modo de actuación particular que expresara las competencias del profesional para desenvolverse en tareas vinculadas a la enseñanza, sí estableció que uno de los objetivos generales de la carrera, era que al concluir sus estudios, los egresados fueran capaces de «ejercer la docencia utilizando los rudimentos esenciales de la pedagogía» (Comisión Nacional de Carrera 2008, 11), lo cual explica que una de las esferas de actuación contempladas fueran las «actividades académicas de la educación superior» (Comisión Nacional de Carrera 2008, 9).

Por su parte, el Plan de Estudios $\mathrm{E}$, que ha sido diseñado a la medida de las necesidades, posibilidades y exigencias particulares de cada Centro de Educación Superior, permitió a la Universidad de Pinar del Río incluir un modo de actuación del egresado que, aunque no logra sintetizar el mismo nivel de generalidad que los anteriores, avanza en el camino de triangular el enfoque formador del jurista. El mismo reza: «También podrán trabajar como docentes en actividades académicas de la educación superior» (Departamento de Derecho 2018, 12).

A pesar de las diferencias apuntadas entre los dos planes de estudios de base ahora vigentes - toda vez que el Plan D está en liquidación, mientras el Plan E avanza en su segundo curso académico- se aprecia la importancia atribuida a formar habilidades para el ejercicio de funciones educativas. La limitación en ese sentido puede ubicarse, en primer lugar, en la falta de sistemática en la forma de reflejar este modo de actuación en los distintos elementos del Modelo del Profesional (V. gr.: problemas que debe afrontar y resolver, así como campos de acción).

Por otro lado, si bien ha tenido un reconocimiento estable el modo de actuación denominado "asesoría jurídica», en los ya analizados planes de estudio se aprecian dificultades para precisar su naturaleza. En el Plan D se plantea que uno de los problemas que debe afrontar y re- 
solver el jurista es «la asesoría, en las entidades de que se trate, sobre lo concerniente al cumplimiento y aplicación de la legislación correspondiente en el desarrollo de la actividad de las mismas» (Comisión Nacional de Carrera, 2008, 8). Más allá del dudoso carácter de problema profesional del enunciado citado, a este parece corresponder la esfera de actuación prevista en "organismos, instituciones, empresas y otras entidades» (Comisión Nacional de Carrera, 2008, 9), con lo cual estaría en línea con la tipología de actividad que se reconoce en la práctica con tal denominación.

Sin embargo, al definir el modo de actuación este Plan de Estudios se debate, sin arribar a una conclusión evidente, en la disyuntiva entre considerar como "asesoría» a la que considera «visión muy reduccionista», aquella que "se les ha otorgado entre nosotros a los juristas que se desempeñan en los organismos, empresas, instituciones, etc.» (Comisión Nacional de Carrera, 2008, 9) y la que entiende como «el nivel básico de competencia de un jurista» y que «realizan casi todos los profesionales del Derecho», cuyas habilidades son esencialmente: "determinar si la situación que se somete a su consideración conforma o no una relación jurídica; en caso de serlo, definir la rama o ramas del Derecho en que se encuentra tutelada; y, previa interpretación de la norma o normas pertinentes, orientar las vías apropiadas para su solución conforme a derecho» (Comisión Nacional de Carrera, 2008, 10).

Esta ambigüedad en los pronunciamientos puede ser asumida como una consecuencia o reflejo de la realidad material. Nótese que los servicios de asesoramiento legal a instituciones y entidades, estatales o no, estuvieron fraccionados, por años, entre la Organización Nacional de Bufetes Colectivos; un grupo de sociedades civiles de servicios, patrocinadas por el Ministerio de Justicia, para prestar servicios a las empresas mixtas y demás formas de asociación económica; las empresas especializadas en entidades del sector del transporte; el asesoramiento propio o interno; y las Consultorías Jurídicas subordinadas a las Direcciones de Justicia de los Órganos de Gobierno Local. A ello debe añadirse la notable dispersión en las regulaciones que ordenaban la actividad, de la cual dan cuenta, en perfecta síntesis, Rivero Morejón y Navarro Pentón $(2017,70)$.

Por su parte, en el Plan E, que es antecedido por el reordenamiento de la actividad de asesoría iniciado en enero de 2018, se aprecia un ligero proceso de corrección de las dificultades de su predecesor. Los principales problemas a resolver por el profesional del Derecho están concebidos con universalidad, de manera que resultan comunes para cualquier especialista del ramo, y otro tanto se hace al enumerar los modos de actuación en «una valedera generalización de las multifacé- 
ticas actividades del jurista» (Departamento de Derecho, 2018, 12). De tal forma que cuando en este documento se alude a la "asesoría», no se está refiriendo al desempeño de aquellos que operan en las esferas de actuación reservada para el ejercicio en "organismos, instituciones, empresas y otras entidades» (Departamento de Derecho, 2018, 12).

Si bien estos niveles de abstracción tienen méritos notables, dejan sin respuesta la cuestión relativa a qué distingue al asesoramiento jurídico propiamente dicho $y$, en consecuencia, cuáles deben ser las adecuaciones para formar las habilidades necesarias que demanda la ejecución del conjunto de acciones a él asociadas, tomando en cuenta, además, que estas pueden variar atendiendo al tipo de persona destinataria de sus servicios (física o colectiva) y de las normas vigentes al efecto.

De la combinación de elementos apuntados resulta que, si bien el profesional del Derecho está capacitado para la labor educativa, sus aptitudes parecen restringidas a los procesos institucionalizados en la esfera de la educación superior. Ello entraña un doble distanciamiento con respecto a las exigencias que, de tales destrezas, puede tener un asesor legal dado, en primer orden, que este precisa de herramientas educativas para ámbitos más informales y, en segundo lugar, que resulta complejo determinar la envergadura que deben tener las mismas puesto que las habilidades básicas de tal modo de actuación no están claramente determinadas en el Modelo del Profesional.

\section{Marco legal de la labor educativa e informativa del asesor jurídico en las cooperativas cubanas}

La asesoría jurídica en Cuba se ordena a partir del Decreto Ley 349 de 24 de enero de 2018, «Del Asesoramiento Jurídico» y la Resolución 41 de 3 de marzo de 2018 del Ministerio de Justicia «Reglamento para el ejercicio de la actividad de asesoramiento jurídico». Dichas normas, si bien contemplan a las cooperativas entre los sujetos destinatarios de este servicio, no tienen como objetivo particularizar en la especialización del desempeño de estos profesionales según las características que singularizan a los sujetos asesorados.

No obstante, en el artículo 5 se establece, con una formulación general, la necesidad de que la actividad de asesoramiento se ajuste, desde el conocimiento, a aquellos elementos que se consideran definitorios para un desenvolvimiento exitoso de los entes asesorados. Al respecto se dispone que "Para el ejercicio de la actividad de asesoramiento jurídico, los juristas tienen que conocer de los objetivos de tra- 
bajo y planificación de las actividades del sistema a que pertenece la entidad donde se desarrolla el asesoramiento legal, y participar del cumplimiento de los objetivos, criterios de medida y planes propios de la actividad de asesoramiento jurídico» (MINJUS, Resolución No. 41 2018).

Si se interpreta el precepto aludido, este permite amparar las exigencias propias de la asesoría jurídica de las cooperativas, toda vez que ellas poseen un conjunto de particularidades que las diferencian de otras empresas. Esta identidad propia, impone a los asesores que asuman compromisos en este campo, un determinado nivel de especialización.

Los elementos que ofrecen contenido a la identidad cooperativa son disímiles (Rodríguez Musa 2017, 39). Ahora vale apuntar, desde este enfoque, que el asesor debe reconocer en la cooperativa un fenómeno socioeconómico integral, que trasciende el mero espacio empresarial y se complejiza sanamente. Ello obedece a que la cooperativa es una empresa, pero en ella también toman forma jurídica vínculos asociativos inspirados en valores nacidos de necesidades sociales, por lo cual, se superponen en su interior, sin conflictos, roles tradicionalmente enfrentados como el de propietario y trabajador, o el de empresario y consumidor. Además, la finalidad de servicio a los asociados que la caracteriza, trastoca la perspectiva tradicional del lucro, también porque la misma no tiene en la responsabilidad social un apéndice impuesto, sino porque es inherente a su naturaleza y estructura institucional. En el mismo sentido, trasciende el hecho de que su funcionamiento se asienta en principios como la voluntariedad, la igualdad, el control democrático, la distribución equitativa, la autonomía y la educación.

Siguiendo el enfoque transversal que se asume en este trabajo sobre la función educativa del jurista, tomando como bases a las funciones del Derecho y la teoría de la actividad, se puede sostener que el asesor está comprometido en su accionar a asumir, no solo el rol de comunicador y educador, sino que, en el caso de las cooperativas, el papel del jurista debe ser coherente con los elementos identitarios de estas formas asociativas.

En estrecha relación con lo anterior, la Resolución No. 41/2018 del Ministerio de Justicia se proyecta en los términos del artículo 6, ya no por el carácter implícito de la labor formativa, sino en pro de asegurarle un espacio propio, al disponer que «Las prioridades del asesoramiento jurídico son las siguientes: (...) 11. Planificación y desarrollo de actividades divulgativas y de capacitación en temas jurídicos». Esta atribución puede emplearse para tratar asuntos relativos a las necesidades propias de las cooperativas, sea por interés del cliente o del asesor. 
Para afrontar esta tarea, el asesor se encuentra respaldado, desde el plano legal, por la posibilidad de superación y la oportunidad de vincularse a la investigación. Ambas constituyen importantes fuentes de actualización para sostener un proceso de formación continua en las habilidades y conocimientos demandados para el desempeño profesional, luego del egreso del pregrado.

En cuanto a la superación, esta, más que una alternativa, está prevista como una exigencia. De tal forma se planifica y se controla, de conformidad con lo previsto en los artículos 10, inciso c) y 11, inciso d), del Decreto-Ley No. 349/2018; así como en el artículo 8, apartado 2 de la Resolución No. 41/2018.

Por su parte, la incorporación a la investigación, aunque no está prevista en los términos de la superación, es objetivamente una alternativa para los profesionales del sector. La Resolución No. 287/2019 del Ministerio de Ciencia, Tecnología y Medio Ambiente, contentiva del «Reglamento para el sistema de programas y proyectos de ciencia, tecnología e innovación», presenta una previsión abierta para que toda persona, colectiva o natural, con capacidad para ejecutar actividades de esta naturaleza, pueda presentar propuestas de proyectos por interés propio en la convocatoria de los Programas destinados a este fin (art. 15).

Así pues, la sistemática legal que le permite al jurista que se desempeña en el asesoramiento superarse, integrarse a la generación de nuevos saberes útiles a través de la investigación y que le dan un espacio en la propia actividad de asesoría para divulgar y capacitar, lo legitiman como un sujeto externo a la cooperativa con especial aptitud para incidir en la dimensión educativa de esta, que es no solo una arista de ella misma, sino una cualidad intrínseca a la figura.

Por ello, entre los principios rectores de las cooperativas cubanas se reconoce "la regla de oro del cooperativismo», exigiéndose en términos relativamente semejantes tanto para las cooperativas agropecuarias (Decreto-Ley No. 365 de 2019, art. 8 inciso i, en relación con el art. 17 inciso d), como para las no agropecuarias (Decreto-Ley No. 366 de 2019, art. 6, inciso h).

De las normas referidas, hay que destacar el acierto de ponderar el derecho a la educación, al reconocerle en esta variante particular. De conformidad con ello, el Decreto-Ley No. 365 de 2019, concibió como parte de la responsabilidad del Estado en el fomento de las Cooperativas Agropecuarias propiciar «la asignación de plazas en los planes de continuidad de estudio para la formación de la fuerza de trabajo calificada de nivel medio, capacidades en programas de nivel de educación superior de ciclo corto y carreras en las universidades, así como 
promueve y gestiona la recalificación y superación posgraduada de sus técnicos» (art. 17, inciso d). Respecto a las Cooperativas No Agropecuarias, el Decreto No. 356, «Reglamento de las Cooperativas no Agropecuarias», que entró en vigor el propio año 2019, le encargó al Ministerio de Educación Superior la elaboración «del programa de preparación y formación sobre los principios de funcionamiento de las cooperativas» (Disposición Final Cuarta).

Sin demeritar el avance que suponen tales regulaciones, conviene hacer notar que tal exigencia recae principalmente en el plano interno de la cooperativa, con el objetivo de promover la formación de sus miembros respecto a las actividades a desarrollar, así como en los principios del cooperativismo; sin embargo, se subvalora la esfera externa del principio en cuestión, su contenido informativo y las potencialidades de los asesores jurídicos para colaborar con su realización.

\section{Algunas propuestas para potenciar la educación, capacitación e información cooperativas en Cuba desde la asesoría jurídica}

A partir de las reflexiones anteriores es posible identificar un grupo de ideas cuya implementación podría contribuir a potenciar la educación, capacitación e información cooperativas desde la asesoría jurídica en Cuba, a saber:

Concebir la labor educativa e informativa como parte del modo de actuación del asesor jurídico

Ante todo, conviene apuntar la ausencia de fundamento para constreñir el actuar educativo de cualquiera jurista al ámbito de la Educación Superior. Ello supone preterir que, entre las funciones del Derecho están la orientación de comportamientos y la educativa (Fernández Bulté 2004, 46), lo cual convierte a cada profesional en un potencial agente formador, a partir de sus conocimientos.

Por tal motivo, la educación jurídica no se restringe al espacio universitario, sino que ha de entenderse como «un proceso consciente de enseñanza y aprendizaje, de acercamiento continuo al derecho para apropiarse de su contenido político, social, ideológico, deontológico, axiológico, normativo y conductual, (...) mediante el estudio de las normas jurídicas y encaminado a la formación ética del ciudadano, sobre la base de la dialéctica de deberes y derechos» (Sierra Socorro 2004). 
En particular, Por cuanto alude a la labor del asesor jurídico, es pertinente precisar que una sistematización de sus actividades fundamentales permite contemplar, dentro de dicho modo de actuación, lo siguiente (Bruch 2016) (Garcìa 2017):

- Diagnosticar: implica la determinación del estado de cualquier fenómeno. Los resultados conseguidos deben funcionar como punto de partida para trazar y ejecutar el plan de acciones destinado a eliminar las dificultades jurídicas detectadas.

- Orientar: se manifiesta cuando se aconseja sobre las opciones y medios jurídicos con que se cuenta para satisfacer sus intereses, esclareciendo dudas y advirtiendo sobre el alcance y posibles efectos jurídicos de las acciones a emprender relativas a sus asuntos.

- Redactar: requiere de la «ingeniería» o creatividad del asesor, para reflejar principios e intereses concretos en documentos de trascendencia jurídica.

- Representar: se configura cuando un cliente, manifiesta su voluntad para que se ejecuten las acciones legales pertinentes que le permitan brindar solución a la situación jurídica en que se encuentra, actuando en interés y por cuenta de esta.

- Supervisar: se materializa fundamentalmente al realizar la vigilancia en favor de la legalidad de los actos o procedimientos desarrollados.

Si bien ninguna de las actividades relacionadas explicita la dimensión formativa del quehacer del jurista encargado de tal función, conviene tener presente que la misma está implícita. Ello es perfectamente comprensible si se advierte que la actividad existe en forma de acciones o grupos de acciones, siendo la acción un proceso que se subordina a la representación de aquel resultado que habrá de ser alcanzado; es decir, un proceso subordinado a un objetivo consciente (Leontiev 1981).

Dada la proximidad que deriva de la relación entre cliente y asesor, se establece un vínculo de confianza que tiene su asiento en el intercambio constante, a fin de equilibrar los intereses del cliente y el interés general expresado en las exigencias legales. Precisamente esta dinámica le atribuye una particular y sistemática labor en la generación y divulgación del saber jurídico al asesor, lo cual le da una especial oportunidad para contribuir a las dos funciones del Derecho apuntadas previamente.

Como señala Añón al referirse a la función de orientación social del Derecho, esta «se pone de relieve cuando se analiza el Derecho como 
forma de comunicación (...) [por lo cual] habría toda una red de mensajes en muchas direcciones dirigidos a persuadir a otro para que siga un modelo de conducta» (Añón 2006, 122). En cuanto a la función educativa, la misma autora asume que se trata de «algo así como un efecto derivado» de la función antes mencionada. En ella el valor de los operadores legales estriba en que, como «agentes que han de aplicar el Derecho acepten los modelos normativos» (Añón 2006, 125), o sea, que sean capaces de entender, respetar y hacer respetar su legitimidad en todos los extremos de su desenvolvimiento.

Si se examinan con detenimiento las disímiles acciones relativas al asesoramiento legal, se aprecia que la comunicación de conocimientos jurídicos está presente de manera constante y que, en razón de su profesión, es él el encargado de la difusión del respeto por la legalidad en su integralidad. Además, como jurista, se convierte en una persona con una importante responsabilidad respecto a ese entramado comunicativo descrito. Es por esto que, a fin de que se asimilen sus conocimientos entre los sujetos asesorados, resultan inestimables las herramientas didácticas que debe adquirir en su proceso formativo.

Reforzar la institucionalidad que sostiene la educación, capacitación e información de las cooperativas desde la asesoría jurídica

La Constitución cubana del 10 de abril de 2019 reconoce, en su artículo 73, que "La educación es un derecho de todas las personas...». En tanto es este derecho, en primera instancia, «responsabilidad del Estado, que garantiza servicios de educación gratuitos, asequibles y de calidad para la formación integral, desde la primera infancia hasta la enseñanza universitaria de posgrado», corresponde al propio Estado crear las condiciones para respaldarlo, no solo desde el punto de vista material, sino también jurídico-institucional ante sus posibles vulneraciones. Para ello, el país está urgido de una Ley de Educación, que organice el ejercicio y defensa de este derecho, con la participación responsable de «la sociedad y las familias», tal como exige la nueva Carta Magna.

Respecto al reconocimiento constitucional del derecho a la información (artículos 53 y 80, inciso i), sostiene Pérez Véliz (2019, p. 63) que su reconocimiento "es condición para garantizar la transparencia en cuatro sentidos: como condición de garantía jurídica, en el entendido de contar con un respaldo legal para exigir el acceso a la información gubernamental; como condición de garantía institucional, en el entendido de contar con un órgano u organismo al que se le pueda re- 
clamar el cumplimiento por el Estado del deber de informar; como condición de garantía jurisdiccional, en el entendido de contar con un proceso jurisdiccional especial, preferente y sumario que permita obligar al Estado coactivamente a cumplir con su deber de informar; y como condición de garantía material, en el entendido de la existencia de unas condiciones materiales mínimas para que cualquier ciudadano pueda acceder a la información pública».

En esta dirección, conviene destacar que el Cronograma Legislativo para el período 2019-2022 (Asamblea Nacional del Poder Popular 2019), aprobado para la implementación de la Constitución, se ha planificado elaborar la «Ley de transparencia y acceso a la información», a fin de regular el derecho de toda persona a solicitar y recibir del Estado información veraz, objetiva y oportuna, así como las garantías a este derecho. Sin embargo, no se prevé en este Cronograma a corto plazo la Ley de Educación.

En la forma en que las cooperativas cubanas se involucran en la materialización de estos derecho fundamentales para dar contenido al principio que nos ocupa, resulta esencial la labor del asesor jurídico, quien debe contribuir a la conciencia de sus miembros en el contenido de los derechos y en su afinidad con la identidad cooperativa; en la responsabilidad de la cooperativa con su concreción; en la articulación de su práctica y defensa desde las normas internas; y en la formalización de los vínculos necesarios —usando instrumentos jurídicos como los convenios- con los centros de educación e investigación oficiales para definir acciones de este tipo, que respondan a las necesidades propias de la asociación.

Para hacer efectivo este propósito, es necesario que la actividad de asesoría jurídica resulte coherente con la naturaleza de las cooperativas, lo cual no ha sido favorecido desde la enseñanza de pregrado del Derecho, donde los planes de estudio han considerado la institución tan solo de forma incidental desde otras materias como el Derecho Constitucional, Agrario o Mercantil, pero nunca desde el Derecho Cooperativo, pese a los avances que en esta dirección ha mostrado Latinoamérica desde mediados del siglo pasado.

Sin embargo, tanto el Plan de Estudios D (en liquidación), como el Plan de Estudios E (en implementación), cuentan con las bondades necesarias para, desde el currículo optativo y desde el posgrado, ofrecer una formación orientada a las particulares exigencias de cada territorio y de cada uno de los modos de actuación del profesional. En particular, para los asesores jurídicos, conviene trabajar en la consolidación de las habilidades que precisan para desarrollar su labor educativa e informativa en las cooperativas. 
Este ha sido el caso, por ejemplo, de la Carrera de Derecho en la Universidad de Pinar del Río (UPR) donde, utilizándose como referentes resultados de investigación previos, se imparte una asignatura optativa sobre "Introducción al Derecho Cooperativo» desde hace seis cursos, se han concluido cinco cursos de postgrado tocantes o relativos a la materia, de los que se han graduado más de 30 asesores jurídicos del territorio, vinculados en su mayoría a la Empresa Provincial de Servicios Legales. A tono con ello, se formalizó desde 2018 un Convenio de colaboración entre esta Empresa y la UPR, contentivo de un Proyecto de Investigación, Desarrollo e innovación destinado a implementar una «Metodología para perfeccionar el proceso de asesoría jurídica de las Cooperativas No Agropecuarias en la provincia de Pinar del Río». El objetivo de este Proyecto, que a futuro podrían generalizarse hacia otros lugares del país es potenciar, desde la labor del asesor, los rasgos que identifican universalmente esta particular forma asociativa.

Por último, es pertinente reflexionar sobre el lugar en que se encuentran los asesores jurídicos de las cooperativas cubanas, quienes desarrollan su función vinculados a entidades diferentes a la cooperativa (V. gr.: Empresa de Servicios Legales; Organización Nacional de Bufetes Colectivos, etc.) y no se conocen casos de cooperativas donde los asesores sean propios, es decir, donde el jurista sea un asociado más, con derechos, deberes y responsabilidades sociales, que con su labor tribute a la realización del objeto social de la entidad. Esta situación de contar con asesor jurídico propio, pese a que es común en las empresas estatales del país y a no conocerse ningún impedimento legal para que también sea así en las cooperativas ${ }^{4}$, parece favorable para la efectividad de la función educativa e informativa del asesor, en tanto aumentaría su compromiso personal con la asociación cuando estos también sean los suyos.

${ }^{4}$ Al respecto vale mencionar que la Dirección de Asesoramiento Jurídico del Ministerio de Justicia (2013), en sus «Indicaciones Metodológicas para el Asesoramiento Jurídico a las Cooperativas No Agropecuarias» advirtió —desde el 1ro. de los principios que las informan-que este asesoramiento "...se hará efectivo a través de la contratación de servicios jurídicos a las Consultorías Jurídicas subordinadas a los Consejos de la Administración Provinciales y las entidades que prestan servicios legales especializados. En dependencia de los resultados que se obtengan al concluir la evaluación de las normas que con carácter experimental han sido aprobadas (...) se autorizarán otras modalidades de asesoramiento jurídico para las mismas». Sin embargo, hasta la fecha no se conoce ninguna disposición jurídica de carácter general que reafirme o decline tal intención. 
Concebir de manera diferenciada la labor del asesor jurídico en materia de educación, capacitación e información

Como ha quedado expuesto, el rol del asesor jurídico está directamente ligado a la realización por parte de la cooperativa del principio que nos ocupa. Sin embargo, aun cuando la actividad de este profesional hace parte de un todo, su desempeño tiene particularidades que deben concebirse de manera independiente.

$\mathrm{Ha}$ de entenderse que el proceso comunicacional que corresponde al asesor, como responsabilidad individual principal y exclusiva, está delimitado en razón de su competencia, por la ciencia del Derecho. A su vez, debe tenerse en cuenta que la materia jurídica no resulta lineal, sino que las relaciones sociales que tutela el Derecho terminan por intersectarse, por lo cual no es posible establecer un catálogo excluyente de ramas que enmarquen su desempeño, en ningún sentido, incluido el de la educación, capacitación e información. Por tanto, la diversidad que se enfrenta en la entidad de las relaciones jurídicas, condiciona el alcance y contenido de la materia legal a tratarse en cada caso.

Como quedó sentado al inicio de este trabajo, la educación tiene carácter de proceso estable y duradero; variable intensidad y metodología; y una considerable complejidad puesto que integra contenidos, habilidades, valores, etc. En consecuencia, las cuestiones susceptibles de un actuar del asesor en tal sentido, pueden concebirse entre las de mayor amplitud, enfocadas a difundir conocimientos generales o específicos, según se precise, entre los socios. Si bien es primordial que se fomenten — con prioridad- los saberes asociados al Derecho Cooperativo, no son estos los únicos reservados al efecto.

Cuando se piensa en la capacitación jurídica, se alude a una preparación concreta encaminada a la superación para perfeccionar aptitudes técnicas o habilidades ejecutivas en actividades de índole profesional. De tal forma, la exigencia que pesa sobre el letrado, está centrada en ciertas cuestiones relevantes para ocupaciones determinadas dentro de la cooperativa. En este sentido piénsese, por ejemplo, en el secretario de la Asamblea General, que puede perfeccionar su labor con algunas herramientas relativas a la redacción de documentos oficiales, o los directivos de la entidad, que pueden hacer mejor su trabajo si reciben una preparación sobre las normas que ordenan las principales actividades que ejecutan: contratos, tributación, relaciones laborales, etc.

En materia de información, ha de precisarse la opinión de los autores sobre la doble implicación, interna y externa, de esta pretensión. Hacia dentro la cooperativa precisa, por su carácter democrático, de un nivel de acceso a la misma que asegure la transparencia de la gestión. 
Siendo así, cualquier proceso legal, o cualquier decisión que revista forma jurídica, cae en la esfera de los contenidos que el asesor debe poner a disposición de todos los socios, siempre que no exista pronunciamiento legal que indique lo contrario.

En la dimensión externa de la información, habría que distinguir qué asuntos jurídicos, y hasta qué punto, conviene que sean divulgados. Como regla, estos ameritan una aprobación expresa para su divulgación. Para precisarlo, primeramente deben seguirse las indicaciones contenidas en disposiciones generales, en especial aquellas que ordenan el sector cooperativo y la actividad socioeconómica que la entidad desarrolla conforme a su objeto social. Además, deben tenerse en cuenta los estatutos y cualquier otra norma interna de la cooperativa.

La conjunción de todas estas actividades de variable contenido deriva en una carga para el asesor que demanda su preparación continua, así como una constante revisión y optimización de su labor.

\section{Conclusiones}

1. Si bien el profesional del Derecho en Cuba está capacitado para la labor educativa, sus aptitudes parecen restringidas a los procesos institucionalizados en la esfera de la educación superior. Ello entraña un doble distanciamiento con respecto a las exigencias que, de tales destrezas, puede recaer sobre un asesor jurídico, en primer orden, porque este profesional precisa de herramientas educativas para ámbitos más informales y, en segundo lugar, porque resulta complejo determinar la envergadura que deben tener estas herramientas, pues las habilidades básicas de tal modo de actuación no están claramente determinadas en el Modelo del Profesional.

2. El marco legal de la labor educativa e informativa del asesor jurídico en las cooperativas cubanas permite amparar las exigencias propias de la asesoría jurídica de estas formas asociativas, cuya identidad impone a los asesores que asuman compromisos en este campo, determinados niveles de especialización. Para afrontar esta tarea, el asesor se encuentra respaldado por la posibilidad de superación y por la oportunidad de vincularse a la investigación.

3. Para potenciar la educación, capacitación e información cooperativas en Cuba desde la asesoría jurídica, conveniente sería: 
- concebir la labor educativa e informativa como parte del modo de actuación del asesor jurídico, la cual no se restringe al espacio universitario, en tanto la necesidad de difundir el respeto por la legalidad en su integralidad está presente de manera constante; pero, para que se asimilen los conocimientos entre los sujetos asesorados, resultan inestimables las herramientas didácticas que debe adquirir el asesor en su proceso formativo.

- reforzar la institucionalidad que sostiene la educación, capacitación e información de las cooperativas, para lo cual el asesor jurídico puede contribuir a la conciencia de sus miembros sobre la afinidad de los derechos fundamentales a la educación y al acceso a la información, con la identidad cooperativa; en la responsabilidad de la institución con su materialización; en la necesaria articulación de su práctica y defensa desde las normas internas; y en la formalización de los vínculos necesarios con los centros de educación e investigación oficiales para concretar acciones de este tipo que respondan a las necesidades de la cooperativa.

- concebir de manera diferenciada la labor del asesor jurídico en materia de educación, capacitación e información, la primera enfocada a difundir conocimientos entre los socios, priorizando el Derecho Cooperativo; la segunda destinada a potenciar las aptitudes técnicas o habilidades ejecutivas en actividades profesionales; y la última, hacia dentro asegurando la transparencia, y hacia fuera distinguiendo, en atención a las normas internas y externas de la cooperativa, qué asuntos jurídicos conviene que sean divulgados.

\section{Bibliografía}

ADDINE FERNÁNDEZ, F. 2006. «El modo de actuación profesional pedagógico: apuntes para una sistematización». En Colectivo de autores, Compilación modo de actuación profesional pedagógico. De la teoría a la práctica. La Habana.

ALFONSO CAVEDA, D. 2014. Modelo del profesional de la carrera de derecho: fundamentación de una propuesta para su perfeccionamiento. Congreso Universidad, III. La Habana.

ALIANZA COOPERATIVA INTERNACIONAL. 1995. Declaración Sobre la Identidad Cooperativa. Manchester. Recuperado el 12 de diciembre de 2009, de http://www.elhogarobrero1905.org.ar 
AÑóN, M. J. 2006. «Funciones del Derecho». En Colectivo de autores, Introducción a la teoría del derecho (págs. 109-127). La Habana: Editorial Félix Varela.

ARNÁEZ ARCE, V. M. 2015. «Educación, formación e infomación. El compromiso cooperativo con la juventud». En V. M. Arnáez Arce, Difusión de los valores y principios cooperativos entre la juventud. Madrid: Dykinson S.L.

ARNÁEZ ARCE, V. M., \& ATXABAL RADA, A. 2015. "La democrazia e l'educazione, valori cooperativi». En V. M. ARNÁEZ ARCE, Difusión de los valores y principios cooperativos entre la juventud. Madrid: Dykinson S.L.

ASAMBLEA NACIONAL DEL PODER POPULAR. 2019. Anexo del Cronograma Legislativo con Propuestas de Leyes para el período 2019-2022. Consultado en http://www.parlamentocubano.gob.cu/wp-content/uploads/ ANEXO-del-Acuerdo-del-Programa-Legislativo-Cuarto-POS-IX-Leg.pdf, el 22 de mayo de 2020.

BRUCH, E. 2016. Marketing de servicios jurídicos a pequeñas y medianas empresas. Recuperado el 24 de junio de 2018, de https://www.tesisenred. net/bitstream/handle/10803/386530/ebm1 de1.pdf.

CAMPOS PÉREZ, Y. y LEÓN GARCÍA, L. 2017. "Análisis crítico a las obligaciones contraídas en el período de formación de las cooperativas no agropecuarias en Cuba», Boletín de la Asociación Internacional de Derecho Cooperativo, núm. 51. DOI: http://dx.doi.org/10.18543/baidc-512017pp261-285.

COMISIÓN NACIONAL DE CARRERA. 2008. Fundamentación introductoria. Plan de Estudios D: Carrera de Licenciatura en Derecho. La Habana: MES.

DEPARTAMENTO DE DERECHO. 2018. Plan de Estudios: «E». Carrera: Derecho. Pinar del Río: Universidad de Pinar del Río.

FERNÁNDEZ BULTÉ, J. 2004. Teoría del Estado y el Derecho.Tomo II Teoría del Derecho. La Habana: Editorial Félix Varela.

GARCÍA, A. 2017. Derecho cooperativo y de la Economía Social y Solidaria . Mérida: Asociación Iberoamericana de Derecho Cooperativo, Mutual y de la Economía Social y Solidaria.

GARCÍA PEDRAZA, L., GARCÍA RUIZ, JG y FIGUERAS MATOS, D. 2018. «Importancia de la educación cooperativa. Una experiencia cubana», REVESCO, Revista de Estudios Cooperativos, núm. 129. DOI: http://dx.doi. org/10.5209/REVE.62881

GONZÁLEZ JIMÉNEZ, O. L. 2005. Determinación del modelo del profesional formado en la Facultad de Agronomía de montaña de San Andrés. Recuperado el 15 de abril de 2020, de www.monografias.com : https://www. monografias.com/trabajos29/modelo-de-profesional/modelo-de-profesional.zip

LEONTIEV, A. 1981. Actividad, Conciencia y Personalidad. La Habana: Pueblo y Educación.

MESA MEJÍAS, M.P. 2019. "Las relaciones entre los sujetos del sector no estatal cubano: el socio-Trabajador por Cuenta Propia en las Cooperativas No Agropecuarias», Boletín de la Asociación Internacional de 
Derecho Cooperativo, núm. 54. DOI: http://dx.doi.org/10.18543/baidc-542019pp131-144.

MINISTERIO DE JUSTICIA (Dirección de Asesoramiento Jurídico). 2013. Indicaciones Metodológicas para el Asesoramiento Jurídico a las Cooperativas No Agropecuarias.

PÉREZ VÉLIZ, A. 2019. "Los derechos de respuesta y rectificación: garantías para la protección del derecho a una información transparente», en PEÑA, V.; PÉREZ VÉLIZ, A.; CALZADA TORRES, M. B. y HERNÁNDEZ AGUILAR, O. (coordinadores): Políticas públicas de transparencia, acceso a la información y rendición de cuentas: acercamientos a las realidades de México y Cuba. Hermosillo: El Colegio de Sonora.

PRIETO VALDÉS, M. 2019. "Las novedades de la Constitución cubana aprobada el 24 de febrero de 2019». Cuadernos Manuel Giménez Abad.

RIVERO MOREJÓN, V., \& NAVARRO PENTÓN, A. G. 2017. «Principales retos del asesoramiento jurídico en la actualización del modelo económico y social cubano de desarrollo socialista». AP y E. Revista cubana de Administración Pùblica y Empresarial , 69-84.

RODRÍGUEZ MUSA, O. 2017. La constitucionalización de la cooperativa. Una propuesta para su redimensionamiento en Cuba. Brasilia-DF: Editorial Vincere Asociados.

SIERRA SOCORRO, J. 2004. La educación jurídica. Propuesta de un sistema de trabajo teórico y metodológico para la formación inicial y permanente de maestros primarios. Tesis en opción al grado de Doctor en Ciencias Pedagógicas. Pinar del Río: Universidad de Pinar del Río.

\section{Legislación}

Decreto-Ley 349 de 24 de enero de 2018, «Del Asesoramiento Jurídico», Gaceta Oficial No. 5 Extraordinaria de 24 de enero de 2018.

Decreto-Ley No. 365 «De las Cooperativas Agropecuarias». Gaceta Oficial No. 37 Ordinaria de 24 de mayo de 2019.

Decreto-Ley No. 366 «De las Cooperativas no Agropecuarias», Gaceta Oficial No. 63 Ordinaria, de 30 de agosto de 2019.

Decreto No. 354 «Reglamento del Decreto-Ley De las Cooperativas Agropecuarias». Gaceta Oficial No. 37 Ordinaria de 24 de mayo de 2019

Decreto No. 356 «Reglamento de las Cooperativas no Agropecuarias», Gaceta Oficial No. 63 Ordinaria, de 30 de agosto de 2019.

Resolución No. 41 de 3 de marzo de 2018 del MINJUS «Reglamento para el ejercicio de la actividad de asesoramiento jurídico», Gaceta Oficial No. 20 Extraordinaria de 5 de marzo de 2018.

Resolución 287 del Ministerio de Ciencia, Tecnología y Medio Ambiente «Reglamento para el sistema de programas y proyectos de ciencia, tecnología e innovación». Gaceta Oficial No. 86 Ordinaria de 8 de noviembre de 2019. 


\section{Derechos de autor}

El Boletín de la Asociación Internacional de Derecho Cooperativo es una revista de acceso abierto lo que significa que es de libre acceso en su integridad inmediatamente después de la publicación de cada número. Se permite su lectura, la búsqueda, descarga, distribución y reutilización legal en cualquier tipo de soporte sólo para fines no comerciales y según lo previsto por la ley; sin la previa autorización de la Editorial (Universidad de Deusto) o el autor, siempre que la obra original sea debidamente citada (número, año, páginas y DOI si procede) y cualquier cambio en el original esté claramente indicado.

\section{Copyright}

The International Association of Cooperative Law Journal is an Open Access journal which means that it is free for full and immediate access, reading, search, download, distribution, and lawful reuse in any medium only for non-commercial purposes, without prior permission from the Publisher or the author; provided the original work is properly cited and any changes to the original are clearly indicated. 